\title{
ENSINANDO ÉTICA NA LICENCIATURA EM EDUCAÇÃO ESPECIAL: UMA EXPERIÊNCIA DE CO-CONSTRUÇÃO DE CONHECIMENTOS
}

\section{Teaching ethics in a special graduation course: an experience of co-construction of knowledge}

Enicéia Gonçalves Mendes

Universidade Federal de São Carlos/Brasil

Correo-e: eniceia.mendes@gmail.com; egmendes@ufscar.br

Recepción: I5 de mayo de 2017

Envío a informantes: 6 de junio de 2017

Aceptación definitiva: II de septiembre de 2017

Resumo: Ética profissional é um tema que dificilmente aparece com destaque nas matrizes curriculares de cursos de formação de professores no Brasil, entretanto, se a finalidade ulterior da educação é a formação da pessoa, se torna importante incorporar as discussões sobre ética na formação de professores. $O$ presente relato descreve a experiência de planejar e ensinar a disciplina Ética, num curso de Licenciatura em Educação Especial, que tem como proposta formar o futuro professor com conhecimento, habilidades e disposição para fazer analisar situações e tomar deliberações pautadas na ética necessária para prover educação de qualidade para todos os estudantes. A metodologia foi planejada para promover a co-construção de conhecimento, processo no qual há interações entre professor e estudantes e entre os próprios estudantes, e que resulta em construção colaborativa de conhecimento. Espera-se contribuir para que os futuros professores identifiquem práticas que promovam o desenvolvimento de si, e dos estudantes do público-alvo da Educação Especial, de suas famílias, de outros profissionais e da profissão de professor de Educação Especial. Ética.

Palavras chave: Educação Especial; Formação de Professores; Educação Inclusiva;

AвsтRact: Professional ethics is a topic that hardly appears prominently in the curricular matrices of teacher preparation courses in Brazil; however, if the 
later purpose of education is the formation of the person, it becomes important to incorporate the discussions about ethics in teacher education. The present report describes the experience of planning and teaching the Ethics discipline in a Special Education Degree course that aims to prepare the future teacher with the knowledge, skills and willingness to analyze situations and take decisions based on the ethics necessary to provide quality education for all students. The methodology was designed to promote the co-construction of knowledge, a process in which there are interactions between teachers and students and among the students themselves, resulting in collaborative knowledge construction. It is hoped that future teachers will be able to identify practices that promote self-development, and the development of the students of the Special Education, their families, other professionals and the profession of Special Education teacher.

KEY wORDs: Special Education; Teacher Preparation; Inclusive Education; Ethics.

\section{Introdução}

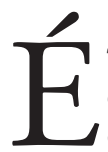

TICA PROFISSIONAL É O CONJUNTO DE NORMAS que formam a consciência do profissional e representam imperativos para sua conduta. Esse é um tema que dificilmente aparece com destaque nas matrizes curriculares de cursos de formação de professores no Brasil, e além disso, os professores brasileiros não possuem, como muitos outros profissionais, um código de ética que regulamente sua profissão. Entretanto, sendo a finalidade ulterior da educação a formação da pessoa, ou sua autonomia pessoal, é importante incorporar as discussões sobre ética na formação de professores considerando-se que esta pressupõe a autonomia da pessoa e uma educação libertadora, que seja aberta a todas as formas de conhecimento e valores, e a consciência de todas as determinações que limitam nossas opções pessoais (Sousa, 20I0).

Devido à importância atribuída a esse tipo de conteúdo na formação inicial de professores, um curso de Licenciatura em Educação Especial, criado em 2009, propôs em sua matriz curricular uma disciplina obrigatória intitulada «Ética e Educação Especial». A experiência aqui relatada foi de ministrar a disciplina no primeiro semestre 20I5, para a turma dos ingressantes em março daquele mesmo ano ${ }^{\mathrm{I}}$.

O caráter inovador dessa proposta residiu no desafio de construir uma discussão qualificada e sistematizada sobre ética, educação e educação especial, num curso de formação de professores, considerando que se trata de um tema que não é muito presente em cursos de formação de professores e, por esse motivo, sem muitas referências sobre como ensinar esse tipo de conteúdo. Em segundo lugar, destaco como os procedimentos didáticos utilizados contribuíram para um processo de co-construção de conhecimento entre professor e estudantes, e entre os próprios estudantes, que contribuíram para a formação dos futuros professores de Educação Especial no sentido de desenvolver autonomia, capacidade de análise crítica, tomada de consciência sobre os múltiplos determinantes da conduta do profissional dessa área e dos processos de decisão baseados em deliberações éticas.

A experiência aqui relatada é resultado de sete anos de desenvolvimento e do plano de ensino dessa matéria pela autora. 
ENSINANDO ÉTICA NA LICENCIATURA EM EDUCAÇÃO ESPECIAL:

UMA EXPERIÊNCIA DE CO-CONSTRUÇÃO DE CONHECIMENTOS ENICÉIA GONÇALVES MENDES

\section{Contexto da disciplina Ética e Educação Especial: o curso de Licenciatura Plena em Educação Especial}

A formação de professores de Educação Especial no Brasil passou a ser realizada em nível superior, com o surgimento das propostas de habilitação nos cursos de pedagogia no bojo das reformas da década de 70, no século xx. Entretanto, este tipo de formação que perdurou até o ano de 2006, foi extinto por meio da Resolução CNE/ CP n. ${ }^{\circ}$ I, que instituiu as Diretrizes Curriculares Nacionais para o Curso de Graduação em Pedagogia (Brasil, 2006), eliminando a possibilidade de formação do professor de Educação Especial no âmbito dos cursos de Pedagogia. A partir de então, muito se tem investido em políticas de formação continuada, majoritariamente na modalidade à distância, com cursos de curta duração, mesmo sem evidências de que esse tipo de formação seja efetivo.

O curso de Licenciatura Plena em Educação Especial-LPEE em tela, foi criado no ano de 2009 com o intuito de oferecer ao país uma alternativa de formação inicial especializada nessa área. Nesta época havia apenas duas universidades públicas com oferta do curso de LPEE, entre oito universidades em todo o país com curso ativo registrado no sistema e-MEC/Ministério da Educação. O curso de LPEE em questão visa a formar um professor de Educação Especial com competências para o trabalho com alunos com deficiência, altas habilidades/superdotação e transtornos globais do desenvolvimento.

A disciplina de Ética e Educação Especial deste curso pertence ao elenco das disciplinas obrigatórias, é de natureza teórica, tem quatro créditos, e totaliza uma carga horária de 60 horas/aula, sendo sempre ofertada no primeiro semestre do curso, ou logo que os alunos ingressam no curso. No primeiro semestre de 2015, participaram 36 estudantes da disciplina, ministrada todas as terças-feiras no período vespertino, ao longo de 15 semanas. Dois estagiários de capacitação docente, um do curso de mestrado e outro de doutorado ${ }^{2}$, da mesma universidade acompanharam a disciplina durante esse primeiro semestre.

\section{Objetivos da disciplina}

Por que estudar ética? Para Sousa (20I0) é importante estudar ética devido a necessidade de se falar, de promover diálogo, aprofundar convicções, buscar consensos entre visões antagônicas, abrir o horizonte para problemas novos, possibilitar a apropriação de conceitos pessoais sobre os mais diversos valores, melhorar a análise de situações complexas e formular planos de ação que beneficiem não apenas o próprio indivíduo, mas, principalmente, sua comunidade.

A disciplina Ética e Educação Especial tem como objetivo geral desenvolver nos estudantes a capacidade de argumentar sobre a importância das questões éticas em Educação Especial, e como objetivos específicos: a) identificar e descrever práticas que atentem para questões legais, éticas da profissão; b) reconhecer a importância das evidências científicas que sustentem práticas profissionais efetivas; c) promover a reflexão sobre a relação entre atitudes, comportamentos e formas de comunicação

\footnotetext{
Os estudantes do curso de mestrado e de doutorado que colaboraram nessa disciplina foram Vivian Santos e David dos Santos Calheiros, respectivamente.
} 
ENSINANDO ÉTICA NA LICENCIATURA EM EDUCAÇÃO ESPECIAL: UMA EXPERIÊNCIA DE CO-CONSTRUÇÃO DE CONHECIMENTOS ENICÉIA GONÇALVES MENDES

sobre as próprias práticas; d) descrever e analisar padrões de prática ética e profissional dentro de situações concretas de trabalho, envolvendo múltiplos papéis, uma variedade de indivíduos e com idade e nível de desenvolvimento diferenciados; e) identificar práticas que promovam o desenvolvimento dos estudantes do público-alvo da Educação Especial, de suas famílias, de outros profissionais, do próprio crescimento profissional e que desenvolvam a profissão de professor de Educação Especial.

Considerando que os alunos recém-ingressam na universidade quando cursam essa disciplina, acrescentamos também alguns objetivos práticos, paralelamente aos objetivos teóricos, para serem atingidos ao final da disciplina, e que são relacionados a interpretação e produção de textos científicos, a saber: a) reconhecer os elementos textuais da escrita cientifica enquanto gênero literário; b) ler, interpretar e destacar ideias e informações de um texto científico; c) elaborar trabalho escrito referenciando ideias ou informações de outros autores, sem plagiar e, d) produzir textos segundo as normas da escrita cientifica que evidenciem a elaboração dos principais conceitos da disciplina.

\section{Conteúdos curriculares e procedimentos didáticos}

Como muitos outros grupos na nossa sociedade atual, gostamos de encontrar respostas simplistas para problemas complexos, e com frequência oferecemos respostas simples a questões éticas: é certo porque é a lei, é certo porque é consistente com nosso conceito de dignidade humana, é certo porque aquilo separa e isso segrega, é errado porque não funciona para todos, etc. Muitas vezes parece impossível sair do senso comum e do pensamento simplista em direção a uma análise mais crítica e ponderada das situações. A proposta geral da disciplina é de oferecer um referencial para a reflexão crítica e análise de situações dilemas, visando a deliberação ética, e não meramente oferecer um manual prescritivo do que é certo ou errado.

Para atingir essa meta o conteúdo foi fragmentado em três unidades. Na primeira unidade, abordamos o objeto da ética, a definição desse conceito e sua relação com o campo da Educação e Educação Especial. Na segunda unidade, adentramos ao campo da Educação Especial e discutimos a ética no campo das relações sociais, educacionais e profissionais, e estudamos as políticas públicas e a missão da Educação Especial; as demandas atuais institucionais e suas restrições, o compromisso com a inclusão social e escolar, os efeitos da rotulação, o desafio do trabalho de equipe, os conflitos nas posições (de estudantes, pais e profissionais), e o desafio de se estabelecer a parceria colaborativa entre todos. $\mathrm{Na}$ terceira unidade, discutimos a ética e o compromisso de construção do código de ética da profissão, seguido dos temas éticos emergentes no campo da Educação Especial (como, por exemplo, a bioética e pesquisa em seres humanos em Educação Especial; genética responsabilidade social e deficiências; advocacia, etc.).

Definido o conteúdo programático da disciplina, teve início o planejamento que se iniciou com a busca e seleção do material didático, e este se constituiu como nosso primeiro desafio, em virtude de serem escassas as produções abordando o tema Ética e Educação Especial. Encontramos apenas um artigo nacional, intitulado "Ética, cidadania e Educação Especial» (Paula, 1996), e, na forma de livros, algumas produções estrangeiras interessantes para a proposta da disciplina, tais como The ethics 
ENSINANDO ÉTICA NA LICENCIATURA EM EDUCAÇÃO ESPECIAL: UMA EXPERIÊNCIA DE CO-CONSTRUÇÃO DE CONHECIMENTOS ENICÉIA GONÇALVES MENDES

of special education (Howe e Miramontes, 1992), Ethical Issues in Developmental Disabitilies (Hayes et al., 1994), Etica y discapacidad intelectual (Pan, 2007), além de uma proposta de código de ética para a profissão do educador especial de uma organização profissional e científica estadunidense, o Special Education Professsional Ethics and Practice Standards (Council for Exceptional Children, 20Io). A busca de material didático foi mais bem-sucedida quando expandimos passamos a abranger materiais que abordassem a questão da Ética em Educação.

Após coletarmos uma quantidade considerável de material, procedemos com a análise destes e constatamos que vários poderiam ser utilizados, embora nenhum por si só fosse suficiente para cobrir o conteúdo pretendido, havendo ainda dificuldade em relação ao acesso, principalmente em relação ao material estrangeiro. Tal fato exigiu um trabalho de seleção do material de acordo com os objetivos de cada unidade, visando traduzir textos interessantes para tornar todo o material acessível. Esse processo resultou na atualidade, num acervo de material didático da disciplina envolvendo I4 artigos teóricos sobre ética e educação e/ou educação especial disponíveis na internet, dois textos traduzidos e adaptados, seis livros nacionais, e três apostilas que correspondem aos guias didáticos completos de cada uma das unidades.

A organização dos guias de cada unidade é feita por aula, de modo que o aluno toma conhecimento a priori do que vai acontecer em todas as aulas daquela unidade. Assim, informações tais como os slides utilizados em aulas expositivas, as exigências nas aulas, a bibliografia, os links de internet para acesso aos vídeos, os textos traduzidos e adaptados especialmente para a disciplinas, as atividades avaliativas, enfim, todas essas informações fazem parte do guia e são disponibilizadas com antecedência para os alunos antes do início de cada unidade, via correio eletrônico.

O planejamento da dinâmica das aulas levou em consideração o perfil dos alunos, e principalmente o fato de que a maioria era proveniente de escolas públicas, não possuía, no geral, o habito de leitura e produção de textos autorais segundo as normas cientificas. Além disso, os estudantes são recém ingressantes em um curso que para muitos deles ainda é desconhecido, e que para a maioria não era a primeira opção de carreira no processo seletivo para ingresso na universidade. Em geral, eles estão satisfeitos em ingressar numa universidade pública reconhecida, mas ao mesmo tempo inseguros, sem saber se irão ou não gostar e permanecer no curso.

Diante desse perfil, foi preciso planejar uma disciplina que motivasse os estudantes, e isso implicou em lançar mão de uma variedade de procedimentos didáticos além de evitar o abuso de aulas expositivas, de leituras complexas e seminários desenvolvidos pelos próprios estudantes. Assim, nosso planejamento previu a organização cuidadosa de cada aula, que deveriam ter as seguintes fases:

a) Fase inicial: a aula inicia com uma breve contextualização do objetivo da unidade, do que já foi estudado e são oferecidos feedbacks de avaliações realizadas em aulas anteriores. Em seguida apresenta-se o que será abordado na aula em questão e os alunos são informados sobre a vinculação da aula com o objetivo da unidade, e sobre a lógica da sequência de atividades. Finalmente, informa-se o que será esperado deles na atividade avaliativa daquele dia.

b) Fase de aquecimento: nessa etapa, em geral, usamos um recurso multimídia (vídeos), uma dinâmica ou uma breve aula expositiva para introdução do assunto. A fase de aquecimento dura no máximo 30 minutos; 
c) Fase de aprendizagem ativa: nessa terceira e última etapa da aula, a sala é rearranjada, e os alunos devem se envolver ativamente em alguma atividade, como por exemplo, um trabalho de grupo, um debate em círculo visando apresentar um painel dos trabalhos do grupo, etc.

Em linhas gerais, essa é a dinâmica das aulas, mas cada unidade tem seu próprio planejamento, e seguir descreveremos como foi a experiência com essa disciplina no primeiro semestre de 2015 .

\section{O objeto da ética e sua relação com o campo da Educação e Educação Especial}

A primeira unidade é o carro chefe da disciplina, e nesse início enfrentamos o desafio de cativar a atenção dos alunos e engajá-los numa discussão, que a princípio para eles é muito árida e distante: aprender o que é ética e sua importância para a formação profissional do educador especial.

Assim, começamos com um exercício em grupo no qual cada estudante deveria dizer aos colegas e escrever o que lhe ocorria ao ouvir as palavras «ética», «moral», «educação» e «educação especial». Ao final foi elaborada coletivamente uma lista das palavras associadas por eles a cada um desses conceitos. Posteriormente, com base nessa lista, eles teriam que construir ma definição do que significava cada um desses conceitos para o grupo. Os estudantes, em geral, consideraram muito difícil a tarefa de definir esses conceitos, reclamaram, solicitaram a possibilidade de melhorar suas tarefas com leituras e consultas à internet. Nós insistimos para que eles tentassem fazer com o que sabiam, pois não havia certo ou errado nessa atividade, e eles seriam avaliados pelo empenho na tarefa.

Depois, sistematizamos o produto desses exercícios, apresentamos isso para a classe e discutimos as definições por ele apresentadas com base no conhecimento de senso comum. Em contraposição, propomos apresentar os mesmos conceitos de acordo com o conhecimento científico. Começamos questionando-os como poderíamos construir conhecimento, e discutimos até que eles cheguem à conclusão que seria a partir da leitura de boas fontes de informação. Assim, e convidamos todos a leitura de alguns textos para aprender a melhorar seus conceitos de ética e moral, e também para aprender porque é importante para um futuro educador estudar ética aprender a argumentar sobre qual é a relação entre ética, educação e educação especial.

Nesse momento, comunicamos que eles teriam de, ao final da unidade, produzir um texto na forma de escrita científica, baseando-se nas leituras e discussões que teríamos sobre os temas «ética», «moral», «educação» e «educação especial». Eles deveriam elaborar um texto relacionando todas essas temáticas, e destacamos que essa produção não poderia ser baseada em resumos, ou copiando e colando trechos de textos de outros autores. Explicamos que o plágio, além de falta de ética é crime, e que o modo que muitos deles aprenderam a fazer produções textuais no passado, já não seria mais adequado na universidade. Prometemos, então, trabalhar para que fosse desenvolvida uma produção textual autoral.

A seguir apresentamos um texto cientifico, na forma de ensaio teórico sobre ética e educação, e questionamos se eles sabiam quais eram as características desse tipo de gênero textual. Exploramos as diferenças e eles apontaram o que achavam estranho 
do texto, como por exemplo as informações entre parênteses referentes a autoria, a lista de referências, os trechos com padrões diferentes de digitação, indicando citações literais, etc. Eles aprenderam assim a identificar o significado das várias convenções da escrita científica.

Posteriormente, realizamos uma breve exposição sobre como ler e fichar um artigo cientifico, extraindo as informações relevantes do texto. A partir de um texto disponível na internet sobre o assunto, fizemos juntos a leitura, discutindo a estrutura geral, e cada parágrafo individualmente, para decidirmos se aquele conteúdo seria relevante, e se iriamos inseri-lo no nosso fichamento do texto, ou se iriamos descarta-lo.

Assim, fomos coletivamente construindo o fichamento, processo que constituiu em extrair excertos considerados relevantes, por se relacionarem ao objetivo de produzir o trabalho do final da unidade, anotar informações tais como sobrenome do autor, pagina do excerto, e ano de publicação. Posteriormente, cada excerto foi codificado em função de seu conteúdo, e um subtítulo foi atribuído a cada excerto.

Concluída essa construção coletiva, os alunos passaram para um segundo texto teórico, o qual eles leram, interpretaram, analisaram e ficharam, em grupo, considerando que nesse início eles ainda poderiam ter dificuldades na tarefa, e que os pares possibilitaram trocas e apoios mútuos, visando a construção desse conhecimento. Cada grupo, fez o fichamento de um texto diferente e apresentou para a classe o produto, sendo que ao final io fichamentos sobre novos textos foram apresentados.

Finalmente, buscando a autonomia na tarefa, cada aluno fichou, individualmente dois outros artigos, entre uma lista de $\mathbf{2} 2$ indicados que relacionavam ética, educação e/ou educação especial.

Todo esse processo foi pensado para levar o estudante a desenvolver habilidades autônomas de ler, interpretar e extrair informações relevantes de um texto. Isso pode parecer elementar, mas muitos alunos provenientes do ensino médio ainda estão familiarizados com a construção de textos através do processo de plágio que, inclusive, nem sempre são selecionados a partir de fontes confiáveis.

O passo seguinte foi solicitar que os alunos produzissem seus próprios textos, como evidencia de que construíram conhecimento sobre o assunto. Em grupo, em posse de fichamentos de vários textos lidos e analisados pelo conjunto dos componentes, eles revisaram os fichamentos, identificaram e relacionaram os códigos que atribuíram a cada excerto, selecionaram os excertos relevantes e os que seriam descartados. Finalmente, um esboço da sequência do conteúdo dos excertos foi proposto, de modo que eles já tivessem um esquema para produzir um texto. Entretanto, apesar de lerem vários textos, eles ainda ignoram as exigências de um texto científico e como elaborar um ensaio teórico.

O próximo passo visou a reforçar o aspecto ético e legal de referenciar ideias e informações que extraímos dos trabalhos de outros autores, uma vez que o conhecimento cientifico sempre é produto do investimento de outras pessoas, e se apropriar dessa produção é ilícito, pois ilude os outros sobre a autoria do trabalho. Tal temática era relevante para colocar em debate o fato de que eles costumavam plagiar textos sem saber que o faziam, ao copiarem e colarem conteúdos sem referenciarem os autores. $\mathrm{O}$ vídeo Um Conto sobre Plágio, versão em português ${ }^{3}$, foi usado e muito apreciado pelos alunos, para nos auxiliar nessa discussão sobre plágio.

Do original Et Plagieringseventyr, disponível em: https://www.youtube.com/watch?v=doiGFwqifsc. 
Em seguida veio o momento de reforçar e sistematizar o conhecimento sobre os componentes da redação científica, através de uma breve aula expositiva que foi oferecida sobre as normas da escrita científica que iríamos adotar (Associação Brasileira de Normas Técnicas, 2002), ilustrando como evitar plágios respeitando a propriedade intelectual, como por exemplo, das ideias que iriamos utilizar na produção do trabalho final dessa unidade.

E assim, em grupos, os alunos produziram um texto final relacionando os temas «ética», «moral», «educação» e «educação especial», tomando como base o conjunto de todos os fichamentos que os componentes do grupo selecionaram e organizaram ao longo da etapa anterior.

O passo final, foi fazer com que os estudantes comparassem seus primeiros trabalhos baseados no senso comum, com os produtos das leituras, reflexões e produções coletivas baseadas nas leituras e análises dos textos indicados. Ao final dessa primeira unidade os próprios alunos comparando seus textos com suas primeiras produções se surpreenderam com a própria capacidade de produzir um texto semelhante ao que encontravam nos livros e artigos. Ao final os grupos de cinco alunos produziram artigos redigidos entre Io a 17 páginas, usando a convenção da escrita cientifica.

\section{A ética no campo das relações sociais, educacionais e profissionais, políticas e a missão da Educação Especial}

O curso prosseguiu para a segunda unidade que envolveu basicamente um conjunto de situações dilemas com as quais o professor de educação especial poderia se deparar, e a tarefa dos alunos foi a de analisar as situações tentando ampliar cada vez mais a capacidade crítica diante de cada situação, incorporando diferentes perspectivas, e incentivando a tomada de decisões colegiadas ao se fazer deliberações éticas.

A análise das situações era precedida por breves aulas expositivas que abordavam em linhas gerais os temas conflitantes a serem analisados, e num dos casos, foi proporcionada a leitura de um texto que abordava a questão das famílias de pessoas severamente prejudicadas. O objetivo dessas atividades consistiu em introduzir e contextualizar as situações dilemas que seriam analisadas pelos grupos.

No primeiro exercício, os alunos assumiam o papel do educador especial e eram solicitados a analisar a situação e a tomar uma decisão, que poderia ser individual ou coletiva. No caso, a situação envolveu decidir entre aceitar ou não em sua sala de recurso para atendimento, a pedido da direção, um aluno com dificuldades acadêmicas e comportamentais, mas que não era considerado do público-alvo da Educação Especial. A discussão aqui passou pela questão do diagnóstico que garante atendimento ao mesmo tempo que rotula e estigmatiza, da possibilidade dos serviços de Educação Especial servirem de mecanismo de exclusão dos alunos considerados indesejados pela escola, das implicações da diluição das parcas verbas destinadas aos alunos do público-alvo da Educação Especial, etc.

$\mathrm{Na}$ situação seguinte, os estudantes foram colocados na condição de diretor de uma escola que solicitara recursos para construir uma rampa para atender a um aluno cadeirante e para reformar uma quadra, mas que recebera apenas metade do recurso e que precisaria então decidir como este seria aplicado. Os estudantes 
deveriam analisar a situação e deliberar o que fazer com o recurso. A discussão desse caso abordava a forma como o diretor tomou essa decisão, se de forma colegiada ou autoritária, e se a deliberação ética neste caso deveria ser baseada no utilitarismo segundo a qual o que é bom para a maioria é bom para todos, e a questão do julgamento de valor quando decidimos entre beneficiar uma pessoa com deficiência garantindo seu direito de ir e vir versus beneficiar a maioria no uso da quadra, etc.

A terceira situação dilema foi semelhante a anterior, mas a demanda feita pela escola à uma secretaria de educação era de implantar dois serviços de atendimento educacional especializado: um para alunos superdotados e outro para alunos com deficiência intelectual. A escola recebera apenas recurso suficiente para implantar um programa e deveria decidir o que fazer com o recurso. Em grupo, novamente, os estudantes analisaram a situação, e apresentaram uma resposta sobre o que fariam na posição de diretor da escola. A seguir, as respostas dos grupos eram apresentadas e discutidas e esperava-se que eles optassem por uma decisão baseada em deliberação colegiada. Em seguida, discutiu-se a questão de educação enquanto investimento no caso de crianças com deficiência, e o papel do educador especializado de advogado do público alvo da Educação Especial no contexto escolar.

A quarta situação envolveu uma situação de um educador especializado que se via as voltas com uma criança com deficiência cuja família dava sérios sinais de negligência, ao ponto de se questionar se o pátrio poder deveria ser mantido. A tarefa dos alunos consistia em analisar possíveis implicações de denunciar ou não o caso para o conselho tutelar, propor possíveis encaminhamentos analisando a viabilidade de cada um desses, e finalmente analisar as implicações se a criança fosse encaminhada para instituições de abrigo, analisar se o Estado brasileiro era violentador e/ou protetor - levando-se em consideração os direitos das crianças e adolescentes com deficiência no Brasil.

O quinto caso de ensino era sobre um aluno com deficiência com comportamentos desafiadores que estava correndo o risco de ser expulso da escola. Os estudantes representaram um júri simulado, no qual fizeram o papel de juízes, advogados de defesa e acusação, testemunhas a favor de manter o aluno na escola (mãe, professora, psicóloga) e testemunhas contra a permanência da criança na escola (mãe de um colega de turma, diretora, professora) além dos jurados. Os alunos planejaram os papeis e os argumentos, atribuíram os papéis e representaram o júri simulado, sendo que o caso foi lido, o juiz apresentou as testemunhas de cada lado, as quais foram interrogadas pelos advogados. Ao final, os advogados agruparam os argumentos, expuseram as posições da defesa e da acusação, e ao final os jurados deliberaram se o estudante iria ser mantido ou expulso da escola.

Essa sequência de exercícios com casos de ensino envolvendo situações dilema foi planejada para levar gradualmente os estudantes a fazerem análises cada vez mais complexas, incorporando na resolução da tarefa alguns princípios, tais como: fazer análises e deliberações colegiadas envolvendo o diálogo com o maior número possível de pessoas, considerando as diferentes perspectivas de todos os atores envolvidos, tentar se colocar no lugar do outro para compreender melhor as situações e posições, e analisar possíveis implicações prós e contras de todas as opções possíveis, para finalmente julgar e decidir que ação tomar, de preferencia de modo colegiado. 


\section{Temas emergentes sobre ética e Educação Especial}

A terceira unidade, foi planejada para ampliar a discussão sobre ética, educação e educação especial. Essa etapa foi iniciada com uma discussão sobre a possibilidade de construção de um código de ética da profissão, tomando-se como referência o documento CEC Ethics and Practice Standards (Council for Exceptional Children, 20Io) que propõe para a profissão de educador especial oito princípios e três conjuntos de padrões para o profissional em relação a três aspectos: aos usuários (alunos do público-alvo da Educação Especial e às suas famílias), ao emprego e à profissão e aos outros profissionais.

Os estudantes fizeram a leitura desse documento, que foi traduzido e adaptado para o português. Em seguida, manifestaram suas dúvidas, discutiram se cada um desses princípios e padrões seriam adaptáveis à realidade brasileira. $\mathrm{Na}$ aula seguinte, divididos em grupo eles criaram um caso de ensino fictício envolvendo uma situação dilema sobre um dos princípios ou padrões do código de ética estudado. Os casos de ensino foram trocados entre os grupos para análise e ao final cada grupo apresentou a análise de seus respetivos casos para a classe.

Em seguida a turma foi dividida em grupos de cerca de seis alunos, sendo que cada grupo deveria ler um livro na íntegra sobre ética e educação, e apresentar na forma de seminário para a turma, incorporando os procedimentos didáticos utilizados até então na disciplina, na forma de exposições que não ultrapassem 45 minutos, associada a exibição de vídeos ilustrativos sobre o tema. Para a discussão, cada um dos cinco outros grupos deveria apresentar uma questão para o grupo que estivesse apresentando o seminário as resposndesse.

Ao final dessa unidade, os alunos ampliaram seus conhecimentos sobre ética, discutindo seis diferentes obras sobre assuntos relacionados, tais como: a bioética e pesquisa em seres humanos (Diniz e Guilhem, 2002); ensaios interdisciplinares sobre teoria e práticas profissionais (Meira, 2006), cuidado e educação (Barbosa, 2009), prática educativa (Ferracini, 2008), alunos problema (Freitas, 20II), cultura (Pena-Vega, Almeida e Petraglia, 20II), formação de professores (Severino, 20II) e cidadania (Souza, 20I0)

\section{Avaliação do processo de aprendizagem dos estudantes}

O sistema de avaliação envolveu várias e diversificadas atividades para que os alunos pudessem demonstrar de diferentes formas o que aprenderam. Eles tiveram a oportunidade de fazer atividades individuais e em grupo, de dialogar bastante, de apresentar trabalhos oralmente e de fazer produções escritas. Ao todo foram adotados três tipos de atividades avaliativas - atividades escritas individuais, atividades em grupo envolvendo debate e produção escrita, e a realização do seminário.

Foram requeridas três atividades avaliativas individuais relacionadas ao exercício inicial, envolvendo produção textual de conhecimento prévio sobre o assunto, além do fichamento de dois diferentes textos. Cada atividade recebeu um conceito de um a dez baseado no empenho do aluno e na qualidade do produto. Ao final, a média dos conceitos atribuídos nessas três atividades foi extraída e compôs a fórmula para o cálculo da média final nas atividades individuais. 
Em relação aos trabalhos em grupo, foram realizadas nove atividades avaliativas relacionadas a resolução das situações dilema, questões de estudo sobre texto e código de ética da profissão. Cada atividade recebeu um conceito de zero a dez e para o computo da média nas atividades avaliativas em grupo foram consideradas as sete melhores notas desse conjunto, das quais foi extraída a média aritmética.

Além dos trabalhos anteriores, os estudantes organizados em grupos apresentaram um seminário ao final da disciplina sobre um livro relacionado ao tema. Cada grupo, recebeu a indicação de um livro. Ao final dessa atividade, cada estudante atribuiu uma nota para o seminário realizado pelos grupos dos colegas, além de justificar os motivos que o levaram a atribuir determinado conceito. O conceito obtido por cada grupo nessa atividade foi alcançado a partir da média dos conceitos atribuídos pelos colegas.

$\mathrm{O}$ conceito final que o estudante recebeu na disciplina foi a média aritmética dos conceitos obtidos nos três conjuntos de atividades (atividades individuais, atividades em grupo e seminário). Os alunos receberam feedback sobre seus pontos fortes e onde precisariam melhorar em relação as produções escritas, orais, trabalhos individuais e em grupo. A avaliação foi realizada de forma continuada ao longo de toda a disciplina de modo que o estudante pode acompanhar seu desempenho e ajustá-lo se necessário.

\section{Conclusões}

Essa disciplina representou um grande desafio pois a princípio exigiu muita pesquisa de material e criatividade na elaboração do plano, uma vez que o assunto era novo, e exigiu experimentação até chegar ao seu formato atual. Muito ainda pode ser melhorado, mas em linhas gerais foi encontrado um caminho para motivar os alunos a dialogar, a considerar diferentes perspectivas, a desenvolver a crítica na análise de situações dilema e a dar relevância as questões éticas na profissão, porque no futuro eles irão se deparar com muitas situações complexas difíceis e imprevisíveis, as quais exigirão capacidade de análise e julgamento moral, e tomada de decisões baseadas em deliberações éticas.

O planejamento da disciplina começa pelo estabelecimento de altas expectativas em relação ao desempenho dos alunos, porque eles são capazes e a aprendizagem irá depender de como o professor se dedica a mediar o processo para que eles sempre consigam aprender o máximo possível. Descobrir como motivar os estudantes, e engajá-los nesse processo de co-construção de conhecimento é um grande desafio o que deve mover o professor na hora de a planejar e ensinar. Os alunos em geral gostam muito da disciplina e manifestam isso na avaliação final que realizada, e se sentem desafiados pelas atividades avaliativas.

Ao término da disciplina construímos juntos habilidades importantes para os alunos, tanto instrumentais, como por exemplo a de elaborar um texto baseado nas normas científicas que muito lhes auxiliará ao longo do curso, como também conhecimento baseado em valores que esperamos os tornem melhores profissionais no futuro. O professor aprende com os alunos a como melhorar sua capacidade como docente.

A Educação Especial na atualidade está entre histórias (MEYEN, I995), pois existe a velha história, baseada no modelo médico, na caridade, no assistencialismo, na segregação e na exclusão, fundamentados em crenças e pressupostos que já não são mais aceitos. E há uma nova história, que ainda está para ser escrita, com um quadro referencial que permitirá aos educadores especializados pensar e agir diferente no futuro. 
As pessoas que entram no campo, hoje, devem conhecer a velha história, para não repeti-la, e ao mesmo tempo precisam se mostrar abertas e empenhadas a ajudar a escrever essa nova história durante suas carreiras profissionais. Esperamos assim, estar contribuindo para formar profissionais que ajudem a construir essa nova história, que consiga melhorar a qualidade da educação em nosso país para todos, e especificamente para pessoas com deficiências, altas habilidades/superdotação e transtornos globais do desenvolvimento.

\section{Referências}

Associação Brasileira de Normas Técnicas - abnt (2002) NBR 6023: Informação e documentação - Referências - Elaboração. Rio de Janeiro, 24 pp.

Barbosa, V. (2009) Da Ética da Libertação à Ética do Cuidado: uma leitura a partir do pensamento de Leonardo Boff. São Paulo: Porto de Ideias, 200 pp.

Brasil (2006) Resolução CNE/CP n. ${ }^{\circ}$ I, de Is de maio de 2006. Institui Diretrizes Curriculares Nacionais para o Curso de Graduação em Pedagogia, licenciatura. Diário Oficial da União, Brasília, DF, I6 maio 2006. Seção I, p. II.

Brasil (20I4) Instituições de Educação Superior e Cursos Cadastrados. Brasília, DF: Ministério da Educação - Sistema e-MEc, 20I4. Disponível em: http://emec.mec.gov.br/. Acesso em: 20 out. 2014.

Council for Exceptional Children (20I0) Ethics and Practice Standards. Disponível em: http://www.cec.sped.org/Content/NavigationMenu/ProfessionalDevelopment/Professi onalStandards/EthicsPracticeStandards/default.htm. Acesso em: 2I mar. 2010.

Diniz, D. e Guilhem, D. (2002) O que é bioética. São Paulo: Brasiliense, 69 pp. (Coleção Primeiros Passos, 315).

Ferracini, A. et al. (2008) Conbecimento, ética e educação: reflexões sobre a teoria e a prática educativa. Jundiaí: In House, roo pp.

Freitas, M. C. (20II) O aluno-problema: forma social, ética e inclusão. São Paulo: Cortez, i27 pp.

Hayes, L. J.; Hayes, G. J.; Moore, S. C. e Ghezzi, P. M. (1994) Ethical Issues in Developmental Disabitilies. Reno: Context Press.

Howe, K. R. e Miramontes, O. B. (1992) The ethics of special education. New York: Teachers College Press, 135 pp. (Professional Ethics in Education Series).

MeIra, A. C. H. (org.) (2006) Ética: ensaios interdisciplinares sobre teoria e práticas profissionais. São João da Boa Vista: UNIFEOB, I25 pp.

Meyen, E. L. (1995) A commentary on Special Education. In: E. L. Meyen e T. Skirtc (eds.). Special Education E Student Disability: an introduction (pp. 7-3I). 4 ed. Denver: Love Pusblishing Company.

PAN, J. R. A. (2007) Etica y discapacidad intelectual. 2 ed. Madrid: Universidad Pontificia Comillas, $304 \mathrm{pp}$.

PAul, J. L. et al. (1997) Ethics and decision making in Local Schools: inclusion, policy, and reform. Baltimore: Brookes, I59 pp.

Paula, L. A. L. (1996) Ética, cidadania e Educação Especial. Revista Brasileira de Educação Especial, Marília, v. 4, n. I, pp. 9I-I09. Disponível em: http://www.abpee.net/homepageabpeeo4_06/artigos_em_pdf/revista4numeroipdf/r4_arto8.pdf. Acesso em: 27 ago. 2015 .

Pena-Vega, A.; Almeida, C. R. S. e Petraglia, I. (20II) Edgar Morin: Ética, Cultura e Educação. São Paulo: Cortez, 4. ed., I75 pp.

Severino, A. J. et al. Ética e formação de professores: política, responsabilidade e autoridade em questão. São Paulo: Cortez, 20II, I49 pp.

Sousa, A. B. R. Ética e Cidadania na Educação; reflexões filosóficas e propostas de subsídios para aulas e reuniões. São Paulo: Paulus, 20IO, I2O pp. (Coleção Ethos). 